\title{
CAPACIDADE DE RETENÇÃO DE LÍQUIDOS APLICADOS A ALTO VOLUME EM DIFERENTES CULTURAS AGRÍCOLAS
}

Luciana Claudia Toscano ${ }^{1}$ José Ednilson Miranda ${ }^{1}$ Marcos Gino Fernandes ${ }^{1}$ Gisele Aparecida Bonacin ${ }^{2}$

\section{RESUMO}

Embora se saiba que os espalhantes-adesivos alteram as características físicas da pulverização de diferentes formas, são escassas informações sobre seus efeitos na capacidade de retenção foliar de pulverizações em cuja mistura foi acrescentado espalhante-adesivo são escassas. Este trabalho teve por objetivo determinar a influência do uso de espalhante-adesivo Energic sobre a capacidade de retenção de líquidos por folhas de goiaba, feijão, pêssego, pimentão, soja e laranja. As diferentes espécies utilizadas foram escolhidas pela sua importância econômica e pelas diferenças existentes quanto às propriedades da superfície foliar de cada uma. Folhas de cada cultura foram pulverizadas até além do ponto de escorrimento com soluções com ou sem espalhante-adesivo Energic. Após o escorrimento, medições do volume retido e das áreas foliares foram registradas e utilizadas para a determinação da capacidade de retenção, cujos dados foram expressos em $\mathrm{mL} / \mathrm{m}^{2}$ de folha. Usaram-se três repetições em delineamento inteiramente casualizado, com fatorial de 6 culturas x 2 níveis de aplicação (sem e com). Para a comparação das médias obtidas, utilizou-se o teste de Tukey a $5 \%$ de probabilidade.

1 Dep. de Fitossanidade, Faculdade de Ciências Agrárias e Veterinárias - UNESP, 14870-000 - Jaboticabal - SP. E-mail: lucianaclaudiatoscano@yahoo.com.br; joseemiranda@ig.com.br

2 Dep. de Biologia Aplicada à Agropecuária - FCAV - UNESP. 
Palavras-chave: pulverização, técnica de aplicação, controle de pragas.

\section{ABSTRACT \\ LIQUID RETENTION CAPACITY APPLIED AT HIGH VOLUME IN DIFFERENT AGRICULTURAL CROPS}

Although it is known that the adjuvants alter the physical characteristics of different ways of spraying, information about their effects on the foliar retention capacity in whose mixture adjuvant was addedare scarce. This study had for objective to determine the influence of the use of the adjuvant Energic on the capacity of retention of liquids by leaves of guava, bean, peach, pepper, soy and citrus. The different species were chosen for their economic importance and for differences on foliar surface properties of each one. Leaves of each culture were sprayed until the run-off point with and without solution adjuvants. After run-off, mensurations of retained volume and foliar area were registered and used for the determination of the retention capacity, with data expressed in $\mathrm{mL} / \mathrm{m} 2$ leaf. Three replications were used with a $6 \times 2$ factorial. For the comparison of the averages in crops, Tukey's test at $5 \%$ probability was used.

Key words: spraying, applying technics, pest control.

\section{INTRODUÇÃO}

$\mathrm{Na}$ tentativa de incrementar o desempenho de formulações de muitos defensivos agrícolas, agentes surfactantes ou adjuvantes são adicionados na calda a ser pulverizada sobre culturas de importância agrícola (Grayson et al., 1996). Amplamente usados, estes produtos interferem a atividade de herbicidas, fungicidas e inseticidas (Chow et al., 1989; Foy, 1992; van Toor et al., 1994).

Embora existam diferenças quanto às suas funções e modos de ıção entre os diversos produtos surfactantes (adesionantes, dispersantes, lumectantes, emulsificantes e espalhantes-adesivos) (Matuo et al., 1989), 
no Brasil todos os produtos com estas funções são considerados como sendo da classe dos espalhantes-adesivos (Arruda, 1985). Os espalhantesadesivos são substâncias que diminuem a tensão superficial do líquido fazendo com que o ângulo de contato da gota com a superfície seja reduzido, aumentando, assim, a área de contato (Matuo et al., 1989).

A eficiência de cobertura da pulverização a baixo e médio volume é favorecida pelo uso de espalhantes-adesivos (Bovey et al.,1987). Isto se deve ao fato, de que, a adição do espalhante-adesivo às gotas isoladas de uma calda provoca uma melhor cobertura e as gotas são mais eficientemente retidas, por ter um espalhamento maior na superfície das folhas. Porém, a pulverização a alto volume promove o espalhamento do líquido pulverizado, levando à saturação da superfície aplicada e ao escorrimento deste líquido para fora da superfície aplicada (Camargo \& Silva, 1990).

A interferência dos surfactantes sobre a deposição do líquido pulverizado e na retenção deste líquido pelas folhas das culturas é particularmente importante quando se trata de pulverização a alto volume, onde o volume de solução pulverizada está próximo de sua capacidade de saturação e o escorrimento pode ocorrer (Grayson et al., 1996).

O problema do escorrimento é importante devido às grandes variações nas propriedades das folhas, que variam com a espécie e, mesmo dentro de uma mesma espécie, com as folhas de diferentes estágios e posições (Johnstone, 1973).

Embora se saiba que os espalhantes-adesivos alteram as características físicas da pulverização de diferentes formas, informações sobre seus efeitos na capacidade de retenção foliar de pulverizações em cuja mistura foi acrescentado espalhante-adesivo são escassas (Webb et al., 1999).

Este trabalho teve por objetivo determinar a influência do uso de espalhante-adesivo sobre a capacidade de retenção de líquidos por folhas de goiaba, feijão, pêssego, pimentão, soja e laranja.

\section{MATERIAL E MÉTODOS}

O ensaio foi realizado no Departamento de Defesa Fitossanitária da Faculdade de Ciências Agrárias e Veterinárias - UNESP, Campus de Jaboticabal, no ano de 1998. 
Em laboratório, determinou-se a capacidade de retenção do líquido pulverizado em folhas de café, goiaba, pêssego, pimentão, soja e tomate, segundo metodologia descrita por Matuo et al. (1989). As diferentes espécies utilizadas foram escolhidas pela sua importância econômica e pelas diferenças existentes quanto às propriedades da superfície foliar de cada uma.

Para simular a pulverização, uma folha de cada cultura, mantida na posição vertical e apoiada em suporte colocado sobre o prato de uma balança com precisão de $1 \mathrm{mg}$, foi pulverizada até além do ponto de escorrimento com soluções com e sem espalhante-adesivo Energic $0,2 \%$. O Energic é um espalhante-adesivo não-iônico-aniônico concentrado solúvel, contendo os seguintes componentes: nonil fexoxipoli(etilenoci) etanol, sal sódico do ácido dodecilbenzeno sulfônico e ingredientes inertes, pertencente à empresa Zeneca .

Após o escorrimento, o volume do líquido retido na superfície da folha foi anotado e, posteriormente foram feitas as medições das áreas foliares em medidor foliar LI-COR, modelo LI-3000A. Os dados foram utilizados para o cálculo da capacidade de retenção foliar, expressa em $\mathrm{mL} / \mathrm{m}^{2}$ de folha.

O delineamento estatístico adotado foi um fatorial $6 \times 2$, inteiramente casualizado, sendo um fator a presença ou não do espalhante-adesivo Energic, e outro fator 6 diferentes culturas (goiaba, feijão, pêssego, pimentão, soja e laranja), com 3 repetições para as culturas de goiaba e feijão e 4 para pêssego, pimentão, soja e laranja. Para a comparação das médias entre as culturas, utilizou-se o teste de Tukey a $5 \%$ de probabilidade.

\section{RESULTADOS E DISCUSSÃO}

A análise de variância do efeito do espalhante-adesivo Energic $0,2 \%$ sobre a capacidade de retenção de líquidos das culturas de goiaba, feijão, pimentão, pêssego, soja e laranja revelou diferenças significativas existentes entre as culturas, o uso do espalhante e a interação destes fatores (Tabela 1).

A retenção de líquidos foi afetada negativamente pela adição de espalhante-adesivo Energic 0,2\% no líquido pulverizado em todas as 
culturas envolvidas no estudo, exceto a soja, quando se efetuou a adição do espalhante-adesivo em comparação com a pulverização isenta do produto (Tabela 2).

Tabela 1. Análise de variância do efeito do espalhante-adesivo Energic sobre a retenção de líquidos por folhas de algumas culturas de importância agrícola .

\begin{tabular}{|c|c|c|c|c|}
\hline \multirow[t]{2}{*}{ Causas de variação } & \multicolumn{4}{|c|}{ Capacidade de retenção de líquidos } \\
\hline & GL & $S Q$ & QM & $\mathbf{F}$ \\
\hline Cultura (C) & 5 & 49675,89 & 9935,18 & $9,27^{* * *}$ \\
\hline Espalhante (E) & 1 & 91314,80 & 91313,80 & $177,14 * *$ \\
\hline Interação CxE & 5 & 20407,74 & 4081,55 & $7,92 * *$ \\
\hline Resíduo & 34 & 17526,54 & 515,49 & \\
\hline \multicolumn{5}{|l|}{ Desdobramentos } \\
\hline E dentro de $\mathrm{Cl}$ & 1 & 14305,90 & 14305,90 & $27,75^{* * *}$ \\
\hline E dentro de $\mathrm{C} 2$ & 1 & 9286,71 & 9286,71 & $18,02 * *$ \\
\hline $\mathrm{E}$ dentro de $\mathrm{C} 3$ & 1 & 58409,26 & 58409,26 & $113,31 * *$ \\
\hline E dentro de C4 & 1 & 12677,36 & 12677,36 & $24,59 * *$ \\
\hline E dentro de C5 & 1 & 2391,31 & 2391,31 & $4,64 *$ \\
\hline E dentro de C6 & & 14651,01 & 14651,01 & $28,42 * *$ \\
\hline C dentro de E1 & 5 & 51534,72 & 10306,94 & $19,99 * *$ \\
\hline C dentro de E2 & 5 & 18548,91 & 3709,78 & $7,20 * *$ \\
\hline
\end{tabular}

** = significativo ao nível de $5 \%$.

A adição de espalhante-adesivo à pulverização a alto volume de plantas de goiaba, feijão, pimentão, pêssego e laranja diminuíram a capacidade de retenção do líquido pulverizado, provavelmente devido ao efeito de escorrimento promovido pelo produto. Este efeito negativo foi observado para as folhas de goiaba, feijão, pimentão, pêssego e laranja. Isto comprova a hipótese levantada por Matuo et al. (1989), a qual considera que o espalhante-adesivo, por sua característica de diminuir a tensão superficial do líquido, ao ser aplicado a alto volume, tende ao escorrimento. Possivelmente, o fato do líquido com menor tensão superficial ser menos retido deve-se ao tamanho dos glóbulos na superfície da folha menor em líquido com baixa tensão superficial, visto que a película 
Tabela 2. Efeito do espalhante-adesivo Energic sobre a retenção de líquidos por folhas de algumas culturas de importância agrícola.

\begin{tabular}{lcc}
\hline Culturas & \multicolumn{2}{c}{ Capacidade de retenção $\left(\mathrm{mL} / \mathrm{m}^{2}\right)$} \\
\cline { 2 - 3 } & \multicolumn{1}{c}{ Sem espalhante adesivo } & Com espalhante adesivo \\
\hline Gojaba $\left(\mathrm{C}_{1}\right)$ & $187,91 \mathrm{bA}$ & $101,02 \mathrm{aB}$ \\
Feijão $\left(\mathrm{C}_{2}\right)$ & $182,11 \mathrm{bA}$ & $112,10 \mathrm{aB}$ \\
Pimentão $\left(\mathrm{C}_{3}\right)$ & $244,94 \mathrm{aA}$ & $69,36 \mathrm{abB}$ \\
Pêssego $\left(\mathrm{C}_{4}\right)$ & $117,32 \mathrm{cA}$ & $35,52 \mathrm{bB}$ \\
Soja $\left(\mathrm{C}_{5}\right)$ & $112,73 \mathrm{cA}$ & $77,20 \mathrm{abB}$ \\
Laranja $\left(\mathrm{C}_{6}\right)$ & $127,06 \mathrm{cA}$ & $39,12 \mathrm{bB}$ \\
\hline
\end{tabular}

Letras minúsculas na mesma coluna e letras maiúsculas na mesma linha quando iguais, não diferem entre si pelo teste de Tukey $(\mathrm{P}>0,05)$.

da gota se rompe com maior facilidade e o escorrimento é maior (Johnstone, 1973). Matuo et al. (1989) verificaram a redução da retenção do líquido pulverizado a alto volume pela adição de adjuvantes. Assim, à medida que se aumentava a concentração, verificou-se menor retenção. Ocampo-Ruiz \& Matuo (1994) verificaram o efeito de espalhantes-adesivos na retenção do acaricida propargite $(0,1 \%$ de Omite $C E)$ em folhas de citros em pulverização a alto volume. Foram medidas a tensão superficial, retenção em folhas de laranjeira e o efeito biológico, em laboratório, sobre o ácaro Brevipalpus phoenicis. Os resultados obtidos indicaram que os espalhantes-adesivos testados diminuíram a tensão superficial e a retenção do acaricida, porém esta redução não se refletiu no efeito biológico. Oliveira et al. (1997) também verificaram que o uso do espalhante-adeviso não melhorou a eficiência do acaricida cyhexatin. Em citros, a utilização de espalhantes-adesivos diminuíram a tensão superficial da água e essa resultou na retenção do líquido pulverizado (Matuo et al., 1989). Ainda estes autores observaram que a água apresentou um fator de espalhamento maior com o uso de Energic que quando comparado a outros espalhantes.

Entre as culturas avaliadas, verificou-se que, quando efetuou-se a pulverização sem o espalhante-adesivo, a folha de soja, apesar da presença de pilosidade, não foi a que apresentou maior retenção de líquidos. 
A folha de pımentão foı a que apresentou maior retenção de líquido. Podese argumentar pelos dados obtidos que a pilosidade característica da folha da soja não foi fator decisivo na retenção do líquido pulverizada. Isto ocorreu porque o tamanho de gotas aplicada foi suficientemente grande para ınular este efeito, ou seja, mesmo com a presença dos tricomas na folha, as gotas do líquido tenderam a coalescer e escorrer. Outro fator que pode influenciar na retenção de líquidos é a molhabilidade de uma superfície, quanto menor a molhabilidade da superfície maior será o ângulo de contato da gota (Camargo \& Silva, 1990), existem folhas que são molháveis, outras pouco molháveis e outras não molháveis pela água. Por exemplo, o feijão (Phaseolus vulgaris) possue para ambas as páginas das folhas o ângulo de contato da água de $50^{\circ}$.

A diferença apresentadas quanto à retenção entre as folhas das culturas avaliadas possivelmente, ocorreram devido às diferenças nas características anatômicas da folha, particularmente com respeito à camada de cutícula da epiderme. Esta camada, é constituída de material lipídico, que serve como barreira à penetração de materiais, particularmente substâncias polares, como a água (Cutter, 1986). A epiderme das folhas apresenta tricomas (glandulares e não glandulares), escamas e papilas frequientemente ativos na absorção foliar, assim, como na saída de água e soluções, e interferem na molhabilidade da superfície da folha (Boaretoo \& Rosolem, 1989). Ainda estes autores referem a outras características da epiderme que são muito importantes na retenção de líquidos, como a estrutura e a quantidade de cera presentes na superfície foliar, pois influem na molhabilidade da referida superfície quando se consideram as pulverizações de substâncias.

Matuo et al. (1989) estudando o efeito de adjuvantes na retenção de água na folha de laranjeira cv. Natal verificaram que os espalhantesadesivos proporcionaram menor retenção do líquido em pulverizações de alto volume.

A maior capacidade de retenção de líquido pelas folhas das culturas analizadas foi verificada no pimentão, quando a pulverização foi isenta do espalhante-adesivo.

Na presença do espalhante-adesivo, os maiores valores de reten- 
ção foram observados em goiaba, feijão, pimentão e soja (Tabela 2). Comparativamente, as culturas de goiaba e feijão apresentaram valores de retenção superiores $(\mathrm{P}<0,05)$ aos de pêssego e laranja. Estas informações podem ser atribuídas à interação entre as características da planta e do espalhante-adesivo, a qual afetou os padrões de pulverização, a deposição e a retenção do líquido pulverizado.

Com a presença de espalhante-adesivo, folhas de goiaba e feijão retiveram maior quantidade de líquido pulverizado do que as folhas das culturas de pêssego e laranja. Neste caso, o espalhante-adesivo, por seu efeito de abaixamento da tensão superficial, pode ter solubilizado a camada cuticular ou interagido com esta de tal forma a alterar suas características de permeabilidade (Bukovac, 1976). Com a pulverização a alto volume, o líquido escorreu mais na presença do espalhante-adesivo que na sua ausência, e as diferenças ficaram por conta de outros fatores morfológicos da folha.

\section{CONCLUSÕES}

O uso do espalhante-adesivo Energic a $2 \%$ em pulverização a alto volume é desaconselhável e desnecessário, pois diminui a tenşão superficial das folhas das culturas avaliadas, favorecendo o escorrimento. Isto não inviabiliza o uso de espalhante-adesivo em aplicações a médio e baixo volume, situação na qual o adjuvante, diminuindo a tensão superficial, provoca uma melhor distribuição das gotas aplicadas.

As informações obtidas com o presente estudo deverão orientar recomendações para a otimização da aplicação de defensivos agrícolas no campo, eliminando o problema de desperdício e fitotoxicidade, visto fornecer uma medida da sensibilidade do desempenho da solução aditivada com espalhante-adesivo sobre as diferentes culturas estudadas.

$\mathrm{Na}$ determinação de concentrações de espalhantes-adesivos utilizados em pulverizações a alto volume é importante levar em conta as características morfo e fisiológicas da cultura-alvo, as quais influenciarão o desempenho do produto. Tal determinação deve levar em conta as propriedades físicas das folhas das culturas e do produto, a generalização implica em perdas econômicas pelo desperdício ou perda de eficiência do produto. 


\section{REFERÊNCIAS BIBLIOGRÁFICAS}

ARRUDA, H. P. 1985. Compêndio de Defensivos Agrícolas. São Paulo: Andrei, 448p.

BOARETTO, A.E., ROSOLEM, C.A. Estrutura do Sistema Vascular em Plantas Cultivadas. In: Adubação foliar. p.8-11, 1989. BOVEY, R. W. et al. 1987. Influence of Adjuvants on the Deposition, Absorption and Translocation of Chlopyralid in Honey Mesquite (Prosopis glandulosa). Weed Science. 31:258.

BUKOVAC, M. J. 1976. Herbicide Entry into Plants. In: AUDUS, L. J. Herbicides - Physiology, Biochemistry, Ecology. London: Academic Press, p.333-364.

CAMARGO, P.N. \& SILVA, O. 1990. Manual de Adubação Foliar. São Paulo: Herba, 256p.

CHOW, P.M.P., GRANT, C.A., HINSHALWOOD, A.M. \& SIMUNDSSON, E. 1989. Adjuvants and Agrochemicals. Boca Raton: CRC Press, 207p.

CUTTER, E. G. 1986. Anatomia Vegetal. São Paulo: Livraria Roca, p.110-121.

FOY, C.L. 1992. Adjuvants for Agrichemicals. Boca Raton: CRC Press, $735 \mathrm{p}$.

GRAYSON, B.T., PRICE, P.J. \& WALTER, D. 1996. Effect of the Volume Rate of Application on the Glasshouse Performance of Crop Protection Agent/Adjuvant Combinations. Pesticide Science, 48: 205-217.

JOHNSTONE, D. R. 1973. Spreading and Retention of Agricultural Sprays on Foliage. In: van WALKENBURG, W., ed. Pesticide formulations. New York: Marcel Dekker, p.343-86.

MATUO, T. \& BABA, K. J. 1981. Retenção de Líquido pelas Folhas de citros em Pulverização a Alto Volume. Científica, 9:97-104.

MATUO, T., NAKAMURA, S.H., ALMEIDA, A. 1989. Efeito de Alguns Adjuvantes da Pulverização nas Propriedades Físicas do Líquido. Summa Phytopathologica, 15:163-73.

OCAMPO-RUIZ, R. A. C. \& MATUO, T. 1994. Efeito de Espalhantes- 
Adesivos na Retenção e na Ação do Propargite sobre Brevipalpus phoenicis (Geijs.) em Folhas de Citros. Anais da Sociedade Entomológica do Brasil, 23:265-270.

OLIVEIRA, C. A. L., MATUO, T., SANTOS Jr., J. E., TOLEDO, M.C 1997. Efeito de Espalhante-Adesivo na Eficiência dos Acaricidas Propargite e Cyhexatin no Controle do Brevipalpus phoenicis (Geijskes) (Acari: Tenuipalpidae) em Citros. Anais da Sociedade Entomológica do Brasil, 26:487-493.

PEREIRA, F.M. \& MARTINEZ JÚNIOR, M. Botânica. In: Goiabas para Industrialização. cp. 2, UNESP. Jaboticabal. p.19.

van TOOR, R.F., HAYES, A.L.; COOKE, B.K. \& HOLLOWAY, P.J. 1994. Relationships Between the Herbicidal Activity and Foliar Uptake of Surfactant-Containing Solutions of Glyphosate Applied to Foliage of Oats and Field beans. Crop Protection, 13:260-270.

WEBB, D.A., HOLLOWAY, P.J. \& WESTERN, N.M. 1999. Effects of Some Surfactants on Foliar Impaction and Retention of Monosize Water Droplets. Pesticide Science, 55:343-389. 